\title{
DESCRIPCIÓN, CLASIFICACIÓN Y ASPECTOS GEOLÓGICOS DE LAS ZONAS KÁRSTICAS DE COSTA RICA
}

\author{
DESCRIPTION, CLASSIFICATION AND GEOLOGICAL ASPECTS OF THE \\ KARSTIC REGIONS OF COSTA RICA
}

\author{
Andrés Ulloa ${ }^{1,2,4 *}$, Teresita Aguilar ${ }^{1}$, Carlos Goicoechea $^{4} \&$ Ronald Ramírez $^{3,4}$ \\ ${ }^{1}$ Centro de Investigaciones en Ciencias Geológicas, Universidad de Costa Rica \\ ${ }^{2}$ Instituto Costarricense de Electricidad (ICE) \\ ${ }^{3}$ Escuela Centroamericana de Geología, Universidad de Costa Rica \\ ${ }^{4}$ Grupo Espeleológico Anthros \\ *Autor para contacto: bribriholds@gmail.com
}

(Recibido: 06/10/2011 ; aceptado: 28/11/2011)

\begin{abstract}
In Costa Rica the karstic phenomenon affects mainly carbonate rocks, constituting $0.85 \%$ of the country's surface, with an approximate area of $431 \mathrm{~km}^{2}$. There are documented at least 9 episodes of carbonate deposition from the Late Cretaceous to Holocene, which include eleven stratigraphic units. These events are related to various geological-tectonic processes, changes in sea level, subsidence and changes in the sediment input. Ten karstic zones and four limestone sites have been defined: 1) North Pacific, 2) Tempisque, 3) South Zone, 4) Central Pacific, 5) Cabo Blanco and Malpaís, 6) Turrialba and Pacuare, 7) Talamanca, 8) Venado , 9) Central Valley, 10) Limón and the isolated karst areas: A) Garza, B) Cerro Huevo Frito, C)Cerro Morro and D) Playa Panama. These karstic features have morphologies which can be exo-karstic, including lapiaz, 'mogotes', karstic-towers, sinkholes and conical karst. The best known endokarstic phenomena are caves, in which it is common the development of speleothems. such as stalactites, stalagmites, columns, flowstones, draperies, calcareous pearls, etc. Serpiente Dormida (Sleeping Snake) cave is the deepest in the country, with $-172 \mathrm{~m}$, the longest is the Bruja - Rectangle - Tururún - Corredores system, with $3872 \mathrm{~m}$ in length. At least 258 caves in limestone have been registered, of which $41 \%$ have been mapped (100 caves). $88 \%$ of the caves in Costa Rica are found in karst areas of the Southern Zone (61\%), Tempisque (17\%) and Venado $(10 \%)$, while the remaining $12 \%$ of caves are distributed in other karstic areas. These areas have special environmental and hydrogeological conditions that must be taken into account as to infrastructure development, and could also be exploited by tourism.
\end{abstract}

Key words: Costa Rica, karst, carbonate rocks, karst regions, limestones, caves.

RESUMEN: En Costa Rica el fenómeno kárstico afecta principalmente a rocas carbonatadas, constituyendo $0,85 \%$ del territorio nacional, con un área aproximada de $430 \mathrm{~km}^{2}$. Se han documentado al menos 9 episodios de depositación de carbonatos, desde el Cretácico Superior al Holoceno, los cuales se incluyen en once unidades estratigráficas. Estos eventos están relacionados con diversos procesos geológico- tectónicos, con cambios en el nivel del mar, subsidencia 
y variaciones en el aporte de sedimentos. Se definieron diez zonas kársticas y cuatro localidades calcáreas: 1) Pacífico Norte, 2) Tempisque, 3) Zona Sur, 4) Pacífico Central, 5) Cabo Blanco y Mal País, 6) Turrialba y Pacuare, 7) Talamanca, 8) Venado, 9) Valle Central, 10) Limón y las zonas kársticas aisladas: A) Garza, B) Cerro Huevo Frito, C) Cerro Morro y D) Playa Panamá. Estas zonas kársticas presentan morfologías características, las cuales pueden ser exokársticas, entre ellas lapiaz, mogotes, torres kársticas, dolinas y karst cónico. Los fenómenos endokársticos más conocidos son cuevas, en las cuales es común el desarrollo de espeleotemas como estalactitas, estalagmitas, columnas, flowstones, draperies, perlas calcáreas, etc. La cueva Serpiente Dormida es la más profunda del país con $-172 \mathrm{~m}$, el Sistema de mayor longitud es la Bruja- Rectángulo- Tururún- Corredores con 3872 m de longitud. Se han registrado al menos 258 cuevas en calizas, de las cuales un $41 \%$ se encuentran topografiadas (100 cuevas). El $88 \%$ de las cuevas de Costa Rica se encuentran en las zonas kársticas de la Zona Sur (61\%), Tempisque (17\%) y Venado (10\%); el restante $12 \%$ de cuevas se distribuye en las otras zonas kársticas. Estas zonas tienen condiciones hidrogeológicas y ambientales particulares que deben ser tomadas en cuenta para el desarrollo de infraestructura, y que también podrían ser aprovechadas por el turismo.

Palabras clave: Costa Rica, karsismo, rocas carbonatadas, zonas kársticas, calizas, cuevas.

\section{INTRODUCCIÓN}

El objetivo de esta investigación es describir las características geológicas y físicas para definir las principales áreas geográficas con karsismo en Costa Rica y que puedan ser utilizadas como una guía para futuros trabajos.

El proceso de disolución de una roca es conocido como "karst" o "fenómeno kárstico" y se ve afectado por una serie de factores como solubilidad y permeabilidad de la roca (primaria o secundaria), acidez $(\mathrm{pH})$, composición química, cantidad de agua y contenido de $\mathrm{CO}_{2}$ (principalmente biogénico). En Costa Rica este proceso de disolución ocurre principalmente en rocas carbonatadas, donde su componente principal es la calcita $\left(\mathrm{CaCO}_{3}\right)$, el cual es un mineral que se disuelve fácilmente ante la presencia de ácidos. El más común es el ácido carbónico $\left(\mathrm{H}_{2} \mathrm{CO}_{3}\right)$, formado por la interacción del agua con el dióxido de carbono presente en el aire o el suelo $\left(\mathrm{H}_{2} \mathrm{O}+\right.$ $\mathrm{CO}_{2} \leftrightarrow \mathrm{H}_{2} \mathrm{CO}_{3}$ ).

Las calcilutitas hemipelágicas del Campaniano-Paleoceno no se tomaron en cuenta para la definición de zonas kársticas, ya que no se ha observado disoluciones que produzcan los fenómenos característicos de sistemas kársticos en estas litologías. Las rocas silíceas, por su parte, presentan cierto grado de solubilidad y pueden originar fenómenos kársticos (Martini, 2000), pero en Costa Rica solo se han reconocido con características de disolución muy incipientes (tipo lapiaz) en monzonitas de la zona de Buenos Aires (Obando \& Kussmaul, 2009; Castillo, 2011) y en algunas lavas. Por esto, las rocas silíceas tampoco fueron consideradas para delimitar las zonas kársticas.

La disolución de las rocas carbonatadas produce morfologías exokársticas y endokársticas distintivas. Entre las formas exokársticas se encuentran: lapiaz (también conocido como karren), mogotes, torres kársticas, depresiones kársticas o dolinas, karst cónico, cenotes, poljes y tinakengs. Los fenómenos endokársticos más conocidos son cuevas y cavernas, las cuales se pueden clasificar de acuerdo con la morfología de los pasajes y es común el desarrollo de espeleotemas (entre los más comunes: estalactitas, estalagmitas, columnas, flowstones, draperies, perlas calcáreas, etc.). Para información adicional sobre estos fenómenos kársticos y los tipos de cuevas por solución se recomienda la obra de Palmer (2007).

\section{PLATAFORMAS CARBONATADAS DE COSTA RICA}

Costa Rica se originó como un arco de islas producto de la subducción a partir del Cretácico Superior. Durante su evolución geológica han existido diversos episodios de depositación de rocas carbonatadas (figura 1), desde el Cretácico Superior hasta el Cuaternario, relacionados con cambios en el nivel del mar y variaciones en la 


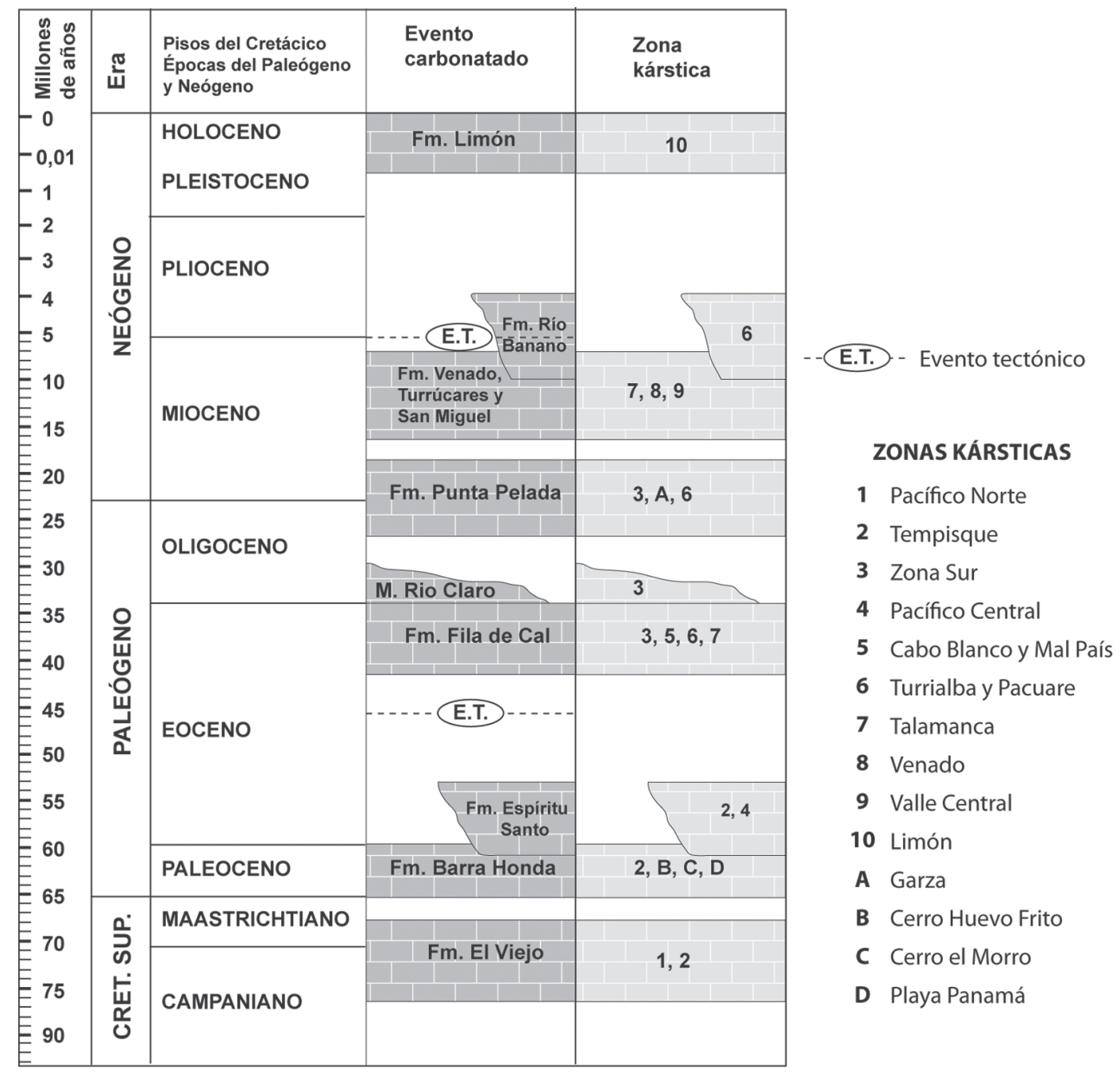

Fig. 1. Columna tectono-estratigráfica en la que se muestran los principales eventos carbonatados de Costa Rica y los sitios geográficos donde se encuentran. Modificado de Sprechmann et al. (1994) y Denyer \& Alvarado (2007).

subsidencia y en el aporte principalmente volcaniclástico.

Durante el Campaniano, un evento tectónico mayor provocó algunos altos estructurales, los cuales conformaron los sustratos con condiciones ecológicas adecuadas (superficies de poca profundidad) para el desarrollo de plataformas carbonatadas como las calizas de la Formación el Viejo (Schmidt-Effing, 1974): areniscas calcáreas y bioconstrucciones de rudistas, ubicadas en el Pacífico Norte. Desde el Maastrichtiano hasta el Eoceno, el proceso de subducción pro- dujo una configuración morfotectónica estable (Seyfried et al. 1991), con predominio de sedimentación carbonatada y sedimentación clástica fina con muy poca influencia continental. Las calizas más representativas de esta etapa corresponden con las Formaciones Barra Honda (Dengo, 1962) y Espíritu Santo (Calvo \& Bolz, 1991). En el Eoceno Medio-Superior, un evento compresivo produjo un levantamiento que afectó varias regiones, favoreciendo el desarrollo de plataformas carbonatadas sobre rocas de ambientes profundos (talud). Estas plataformas se encuentran constitui- 
das por calizas con macroforaminíferos (principalmente los géneros Nummulites, Lepidocyclina y Discocyclina), agrupadas en la Formación Fila de Cal (Sprechmann et al., 1993). En el Oligoceno Superior se produjo un cambio en la sedimentación, de marina profunda a nerítica, evidenciada en varias localidades del país como Jesús María, Barbilla, Punta Pelada y Corredores. Están representados estratigráficamente por la Formación Punta Pelada (Baumgatner et al., 1984) y el Miembro Río Claro (Yuan, 1984), y constituidas principalmente por sedimentos carbonatados (grainstones y packstones de rodolitas, algas y foraminíferos). El proceso de somerización y consecuente emersión continuó durante el Mioceno, por lo que se dio la erosión de las tierras emergidas, lo cual tuvo como resultado la depositación de sedimentos clásticos de origen continental en el arco externo y en su frente, inhibiendo o limitando la depositación de rocas carbonatadas. Debido a esto, durante el Mioceno solo se dan eventos carbonatados aislados, constituidos principalmente calizas bioclásticas como la Formación Venado (Malavassi \& Madrigal, 1970) en San Carlos, las formaciones San Miguel (Carballo \& Fischer, 1978) y Turrúcares (Castillo, 1969) en el Valle Central, algunas facies carbonatadas de la Formación Río Banano (Taylor, 1975) y calizas que se correlacionan con la Formación San Miguel en Talamanca. Durante el Plioceno, la colisión de la dorsal del Coco causó un evento compresivo que produjo un levantamiento general, restringiendo la depositación en cuencas de sedimentación marina en el territorio nacional a las regiones cercanas a las costas actuales (Fischer \& Aguilar, 1994). En el sector del Pacífico, esta sedimentación está representada por los depósitos clásticos de las formaciones Montezuma (Dengo, 1962) y Charco Azul (Olsson, 1942). En el Caribe se desarrollaron facies clásticas y carbonatadas en la formación Río Banano (Taylor, 1975) (Mioceno), permitiendo en algunos casos el desarrollo de parches arrecifales. Estos depósitos carbonatados continuaron en el Pleistoceno hasta el Holoceno y están representados por la Formación Limón (Bottazzi et al., 1994, redefinida por McNeill et al., 2000 como miembro Moín).

\section{ZONAS KÁRSTICAS DE COSTA RICA}

La primera mención de fenómenos kársticos de Costa Rica se da en el año 1902, cuando el diccionario geográfico de Félix Noriega menciona los pozos de Barra Honda (Goicoechea et al., 2009). Goicochea (1970), con base en criterios geográficos reconoce 6 zonas kársticas bien definidas, además de algunas zonas aisladas, detallando las cuevas o reportes existentes por zona. Mora (1986, 1987) describe brevemente 15 zonas kársticas para el territorio nacional, de acuerdo con la edad de las calizas. Ulloa (2009) describe nueve zonas kársticas utilizando criterios geológico-geográficos, las cuales fueron la base para el presente estudio.

En este trabajo se reconocen diez zonas kársticas y algunas zonas aisladas (figura 2), las cuales se describen en orden estratigráfico: 1) Pacífico Norte, 2) Tempisque, 3) Zona Sur, 4) Pacífico Central, 5) Cabo Blanco y Mal País, 6) Turrialba y Pacuare, 7) Talamanca, 8) Venado, 9) Valle Central, 10) Limón y las zonas kársticas aisladas A) Garza, B) Cerro Huevo Frito, C) Cerro Morro y D) Playa Panamá. Estas zonas kársticas se describen a continuación, enfatizando aspectos como ubicación, extensión, origen geológico, características endo y exokársticas.

Con base en el mapa geológico de Denyer \& Alvarado (2007), algunos reportes de rocas calcáreas de diversos autores (Fisher \& Pessagno, 1965; Anónimo, 1975; Mora, 1986; Varela, 1990) y observaciones propias de los autores se determinó que el territorio nacional se encuentra constituido aproximadamente por un $0,85 \%$ de rocas carbonatadas que ocupan un área de $430 \mathrm{~km}^{2}$, mucho menor al área estimada por Kueny \& Day (2002) de $2000 \mathrm{~km}^{2}$. El Cuadro 1 muestra el número de cuevas, área y porción del territorio nacional estimada para cada una de las zonas kársticas. 


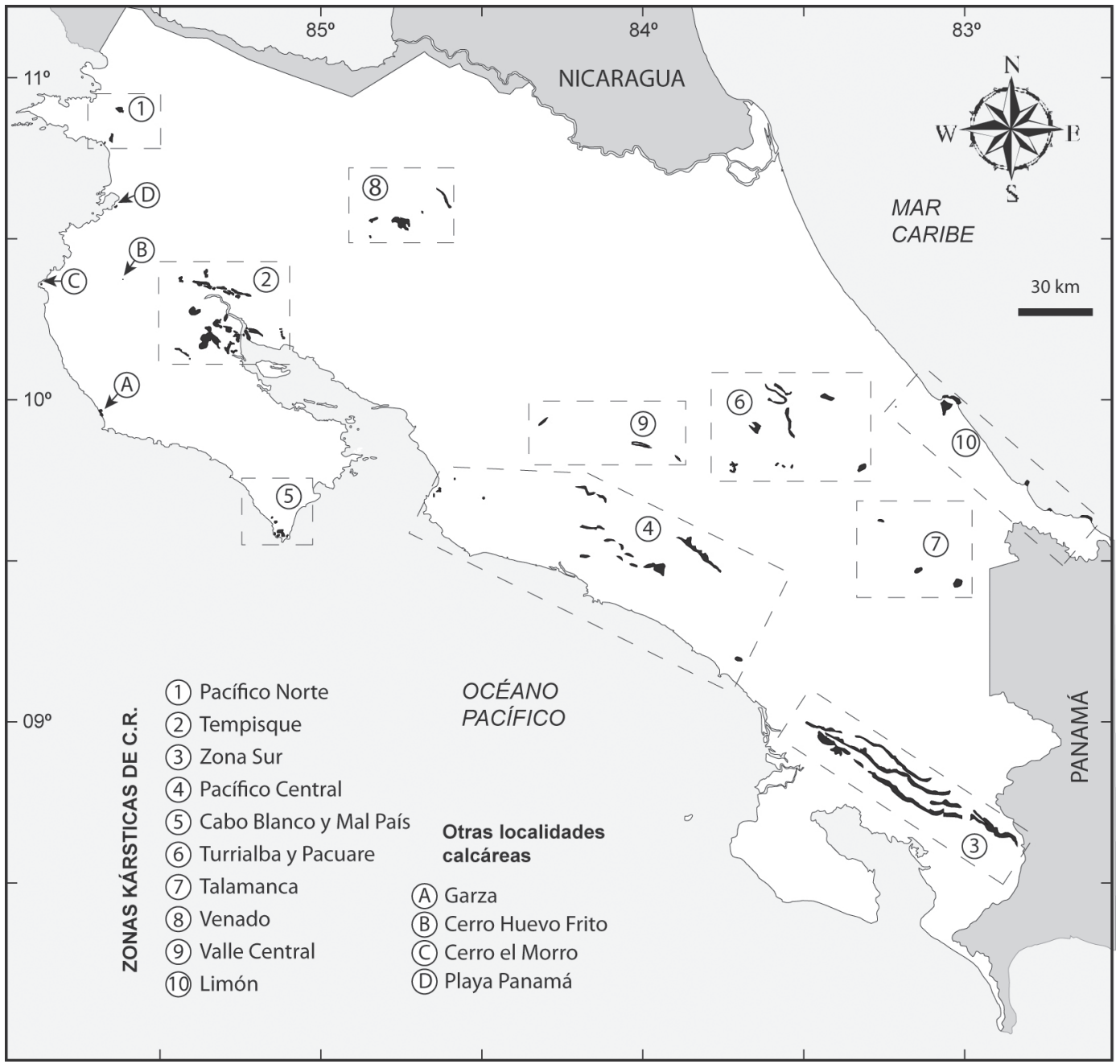

Fig. 2. Zonas kársticas de Costa Rica. Base geológica modificada de Denyer \& Alvarado (2007)

\section{Pacífico Norte}

Las calizas afloran en los acantilados del sector sureste de la península de Santa Elena. Son calizas someras, bioclásticas y arrecífales con abundantes rudistas en posición vital, incluidas en la Formación El Viejo (Cretácico Superior) (Baumgartner et al., 1984), con un área aproximada de $5 \mathrm{~km}^{2}$. Presentan poco desarrollo kárstico, principalmente disolución en la superficie, evidenciado en una topografía irregular. Por la edad y el tiempo de exposición de estas calizas, es posible que exista un paleo-karst, sin embargo, son necesarios más estudios en esta zona.

\section{Tempisque}

Esta zona kárstica se extiende a ambos lados del río Tempisque y tiene un área aproximada de 
Cuadro 1

Número de cuevas, área y porción del territorio nacional de cada una de las zonas kársticas

\begin{tabular}{ccc}
\hline Zona kárstica & $\begin{array}{c}\text { Área } \\
\left(\mathrm{km}^{2}\right)\end{array}$ & $\begin{array}{c}\text { Número de } \\
\text { cuevas }^{1}\end{array}$ \\
\hline Pacífico Norte (1) & 5 & 0 \\
Tempisque (2) & 80 & 44 \\
Zona Sur (3) & 185 & 156 \\
Pacífico Central (4) & 57 & 8 \\
Cabo Blanco y & 5 & 5 \\
Mal País (5) & 38 & 5 \\
Turrialba y Pacuare (6) & 10 & 0 \\
Talamanca (7) & 21 & 26 \\
Venado (8) & 6 & 6 \\
Valle Central (9) & 20 & 8 \\
Limón (10) & 3 & 0 \\
Otras (A, B, C y D) & 430 & 258 \\
Total &
\end{tabular}

${ }^{1}$ Base de datos del Grupo Espeleológico Anthros, 2011

$80 \mathrm{~km}^{2}$, por lo que llega a ser la segunda zona kárstica más grande de Costa Rica. Se extiende desde Colorado de Abangares hasta Nicoya-Santa Ana. Las rocas calcáreas se incluyen en las formaciones El Viejo, Espíritu Santo y Barra Honda. En el sector de Colorado de Abangares, cerro Cebollín y Ballena (al NW de la zona) y en los alrededores de Santa Ana de Belén afloran turbiditas calcáreas y calizas arrecifales pertenecientes a la Formación el Viejo. La Formación Espíritu Santo aflora en los cerros del mismo nombre, y son calizas de macroforaminíferos y algas rojas del Paleoceno Superior-Eoceno Inferior (Calvo \& Bolz, 1991).

La Formación Barra Honda está constituida por calizas de plataforma (Mora, 1981; Calvo, 1987), a las cuales Bandini et al. (2008, figura 2) le asignan una edad Paleoceno Superior.La mayoría de fenómenos kársticos reconocidos en la zona de Tempisque se desarrollan en las calizas de la Formación Barra Honda. El karst de esta zona es caracterizado por la presencia de mogotes (figura 7 D), los cuales llegan a alcanzar alturas de hasta $481 \mathrm{~m}$ sobre las planicies del Tempisque y presentan importantes depósitos coluviales que suavizan

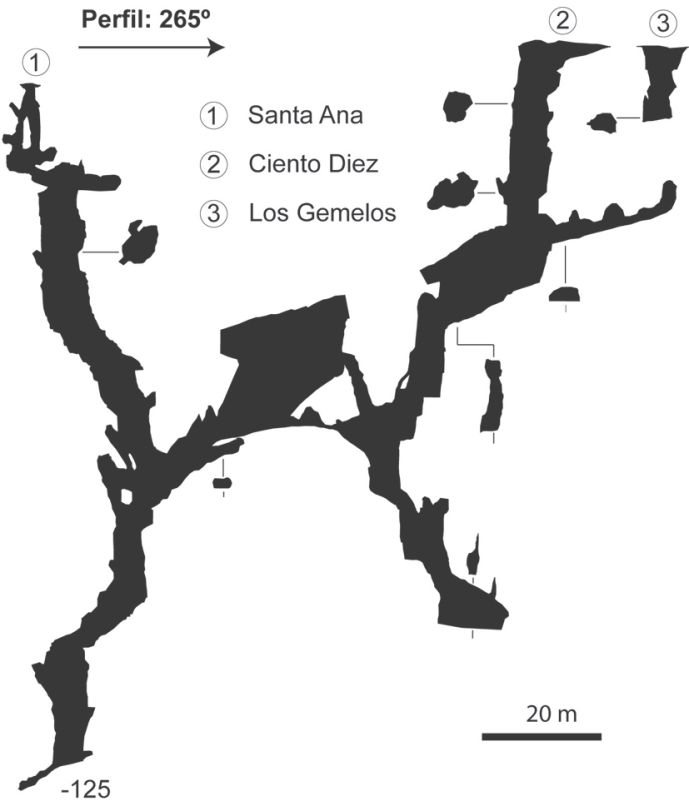

Fig. 3. Perfil del sistema Santa Ana, Pozo 110 y Los Gemelos, ubicados en el cerro Barra Honda $\left(-85.35^{\circ}, 10.17^{\circ}\right)$, zona kárstica Tempisque. Nótese el dominio de pasajes verticales (característicos de cuevas en zonas vadosas) en el sistema, el cual alcanza una profundidad de $-125 \mathrm{~m}$. Modificado de Hampka et al. (1992)

su morfología. Además se presentan campos de lapiaz, karst cónicos, cascadas de travertino, dolinas, surgencias, quebradas ciegas y cuevas (Wells, 1974; Mora, 1978, 1981; Rivier, 1983; Hempel, 1989; Goicoechea, 1989).

En esta zona kárstica se han reconocido 40 cuevas. Las del cerro Barra Honda presentan un importante desarrollo vertical, con un gran número de pozos y la mayoría se encuentran controlados por fracturas y fallas (Mora, 1981). Los pozos son característicos de la zona vadosa y por lo general se encuentran bloqueados a profundidad por barro y bloques, por lo que hasta ahora no se ha alcanzado el nivel freático (Hempel, 1989). El pozo más profundo registrado es el Sistema Santa Ana-Pozo 110 (figura 3), con -125 m (Hampka et al., 1992). Se reconocen estalactitas, estalagmitas generalmente blancas, pero con coloraciones desde naranja hasta rojo, grandes columnas de flowstones, pilares, y perlas calcáreas, entre otros espeleotemas (Mora, 1981; Hempel, 1989). 


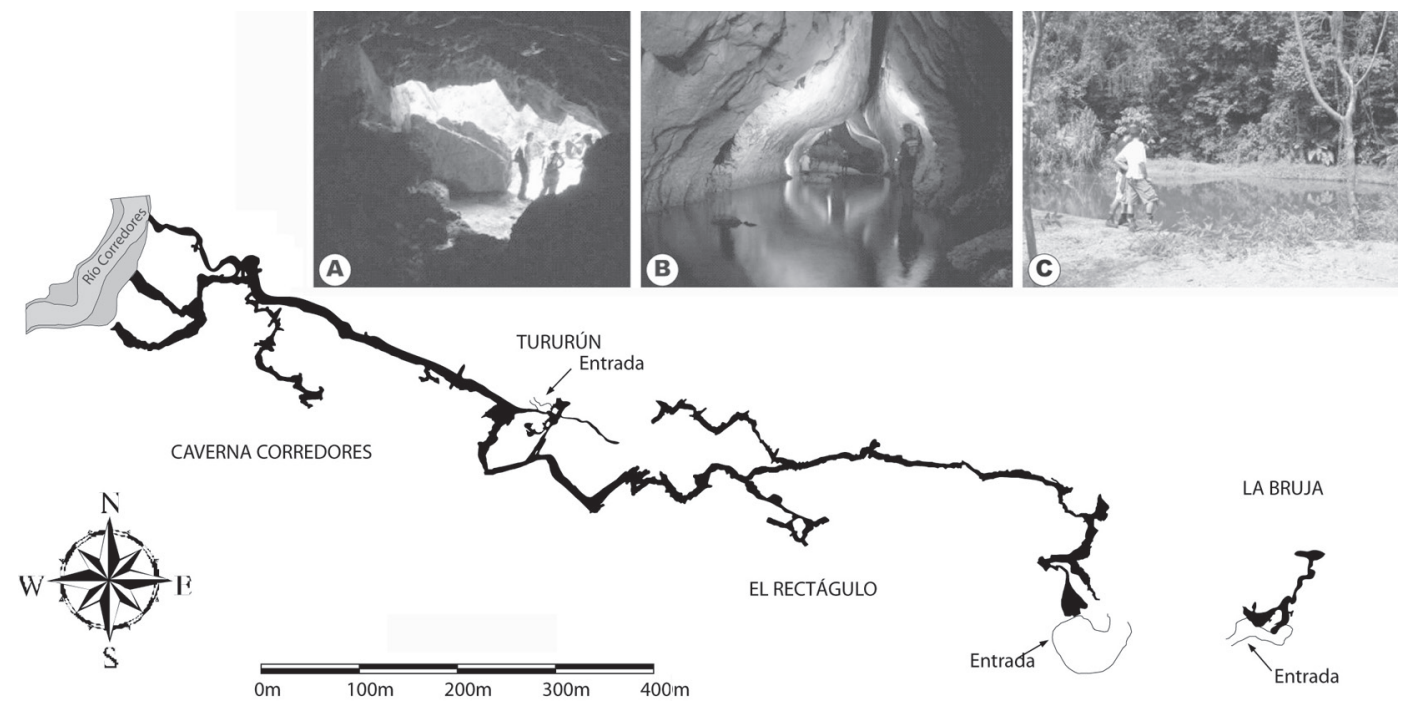

Fig. 4. Sistema kárstico del Cerro Corredor $\left(-82.91^{\circ}, 8.66^{\circ}\right)$, que presenta un patrón alineado a lo largo de fallas. Plano del sistema (modificado de Peacock \& Hempel, 1993): A) Pasaje abandonado dentro de la caverna. B) Falla a lo largo de la caverna Corredores. C) Sumidero La Bruja.

\section{Zona Sur}

Esta es la zona kárstica de mayor extensión de Costa Rica, la cual abarca desde el río Grande de Térraba hasta la frontera con Panamá, a lo largo de la Fila Costeña, con una superficie kárstica de aproximadamente $185 \mathrm{~km}^{2}$. Afloran calizas del Eoceno Medio a Superior (Malavassi, 1961) de la Formación Fila de Cal (Unidad Cajón, Formación Brito sensu Dengo, 1962). Para el Oligoceno se encuentran calizas tipo grainstone y packstone incluidas en la parte inferior de la Formación Térraba (Yuan, 1984) y posiblemente se encuentran calizas someras correlacionables con la Formación Punta Pelada. Generalmente estas unidades carbonatadas se presentan como sobrecorrimientos a lo largo de la Fila Costeña (Mora, 1979; Fisher et al., 2004; Sitchler et al., 2007; Morell et al., 2008).

La Zona Sur es la que presenta mayor número de cuevas reportadas en Costa Rica, con un total de 156 (cuadro 1). Entre las principales características kársticas de la zona se encuentra la presencia de dolinas (figura $7 \mathrm{C}$ ), valles secos, lapiaz, ríos encañonados, sumideros, surgencias, cascadas de travertino (figura 7 A) y cuevas. En la cuenca del río Corredores, Hempel et al. (1993) se reportan la existencia de sistemas semicerrados y cerrados (sin flujo de agua superficial) para los sectores $\mathrm{La}$ Bruja - Corredores (figura 4) y Quebrada Seca, respectivamente. En la cuenca del río Corredores y río Claro, las cuevas tienen un dominio predominantemente horizontal, generalmente muestran ríos hipogeos con importantes caudales, algunos sifones (figura $8 \mathrm{~B}$ ) y presentan un patrón característico de cuevas en rocas fracturadas (figura $8 \mathrm{~A}$ ), desarrolladas principalmente recorriendo fallas inversas a lo largo de la Fila Costeña. En algunas cuevas, Gilli (1994) describe indicadores de fallamiento activo como el fracturamiento de concreciones calcáreas y el desplazamiento de galerías. En las cavernas de Corredores y Emus se encuentran pasajes inactivos que tienen una diferencia de elevación de aproximadamente $25 \mathrm{~m}$ con respecto al nivel base regional y podrían asociarse a un rápido levantamiento durante el Cuaternario que afectó el sistema kárstico (Hempel et al., 1993; Gilli, 1994; 1996). El sistema kárstico con mayor recorrido mapeado es la Bruja - Corredores con 3872 metros de pasajes medidos. En el sector de Miramar de Abrojo y fila Zapote, las cuevas presentan un dominio principalmente vertical (figura 8 D), característico de la zona vadosa. En la Fila Zapote se encuentran pozos profundos (p. ej. 


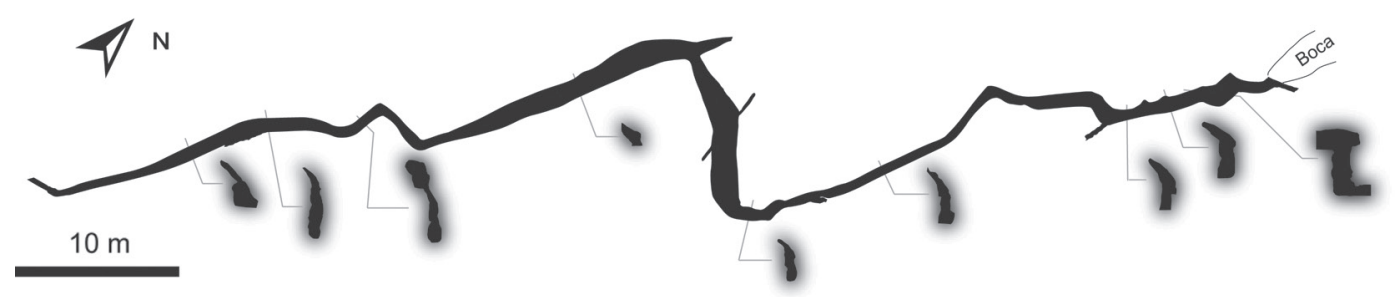

Fig. 5. Plano de la Cueva Huecos, donde se nota un patrón a lo largo de fracturas $\left(-83.62^{\circ}, 10.00^{\circ}\right)$, a orillas del río Bonilla, zona kárstica Turrialba y Pacuare.

Sima Gayabi, -142 m) con potencial para cuevas más profundas (Hapka et al., 1992) y en la zona de Miramar de Abrojo se encuentra la cueva más profunda conocida hasta el momento en Costa Rica, La Serpiente Dormida, con una profundidad de -172 m. En el sector de Cajón, la Cueva del Pizote es un pozo de $-40 \mathrm{~m}$ que sigue la dirección de una fractura (Gilli, 1994). La otra cueva reconocida en este sector es la cueva La Danta, la cual tiene pasajes freáticos entrelazados.

En las cuevas de este sector se han reconocido diversos espeleotemas, los más comunes son estalactitas, estalagmitas y columnas, pero también ha sido posible reconocer perlas calcáreas, rimstones, flowstones, draperie y pajillas, entre otros (figura 9 A, B, D). En la cueva Emus, Hempel et al. (1993) reportan además la existencia de cristales de yeso.

\section{Pacífico Central}

Esta zona abarca las calizas de Quebrada Ganado, cerca de Tárcoles, en su extremo oeste, hasta las calizas de Faralla, al norte de Uvita, en su extremo sureste, que cubren un área aproximada de $57 \mathrm{~km}^{2}$. En la localidad de Damas, Malavassi (1961) determinó una edad Eoceno Medio para las calizas, con base en los macroforaminíferos. En los alrededores de Quebrada Ganado, Soto (1985) y en la localidad de Bola, Carara (G.J. Soto, 2011, com. pers.) se reportan calizas alodápicas. En la Quebrada Concha, Bolz \& Calvo (2002) restringen la edad de las calizas al Eoceno Medio e indican que estas calizas corresponden a una secuencia de plataforma marginal. Granados
\& Aguilar (1983) describen las calizas de Savegre como calizas arrecifales, masivas, de coloración blanco amarillenta, que podrían correlacionarse con la Formación Fila de Cal. En la Fila Chonta, Calvo \& Bolz (1991) reportan calizas con macroforaminíferos y algas rojas que se incluyen en la Formación Espíritu Santo (Paleoceno SuperiorEoceno Inferior). En la confluencia de los ríos Cotos y Paquita, (G.J. Soto, 2011, com. pers.) afloran calizas, que de acuerdo con las relaciones estratigráficas podrían corresponder con la Formación Fila de Cal, o Espíritu Santo.

Las zonas kársticas más conocidas en este sector corresponden a la zona de Damas y Savegre, pero también existen reportes de cuevas en Santa Juana, Providencia y en la zona de Los Santos. Las manifestaciones kársticas se caracterizan por la presencia de dolinas, lapiaz (figura $7 \mathrm{~B}$ ), sumideros, surgencias y cuevas.

Se han reconocido 11 cuevas, y entre estas la Olla Quemada (en Piedras Blancas) es la de mayor desarrollo, con una longitud de $346 \mathrm{~m}$ y alcanza una profundidad máxima de $-57 \mathrm{~m}$, con respecto a la boca. Generalmente las cuevas están controladas por la dirección de buzamiento y en algunos casos presentan un importante relleno con sedimentos cuaternarios que colmataron las cuevas y luegofueron parcialmente erosionados.

\section{Cabo Blanco y Mal País}

Esta zona kárstica se ubica al sur del Golfo de Nicoya, donde afloran aproximadamente 5 $\mathrm{km}^{2}$ de superficie kárstica. Calvo (1987) indica para este sector, un sistema de rampa carbonatada 


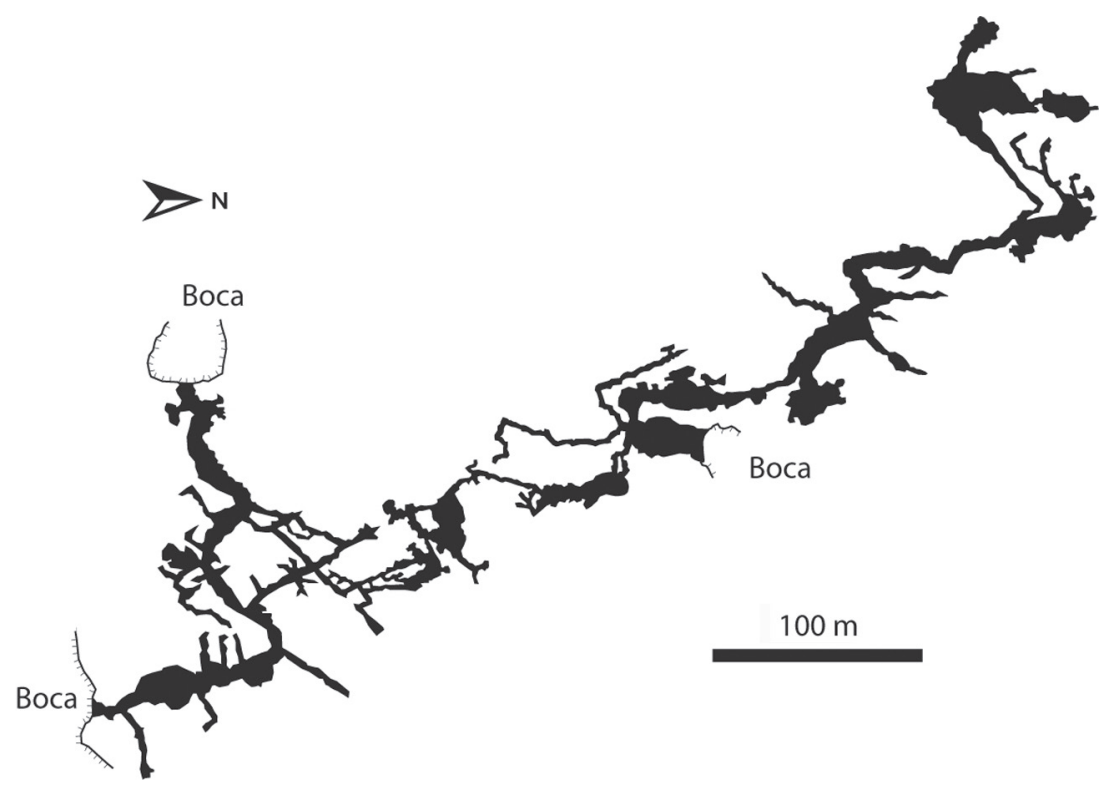

Fig. 6. Caverna de Gabinarraca, Venado $\left(-84.77^{\circ}, 10.56^{\circ}\right)$. Se caracteriza por una red de pasajes alineados a lo largo de fracturas. Tiene un recorrido de $2741 \mathrm{~m}$. Modificado de Goicoechea (2008).

constituida por calizas con macroforaminíferos y algas calcáreas del Eoceno Medio-Superior Además, sedimentos carbonatados alodápicos en forma de rellenos de canal submarino del Eoceno Medio. Las rocas carbonatadas de este sector se incluyen en la Formación Fila de Cal.

En esta zona se reconocen pequeñas dolinas, torres kársticas, superficies de lapiaz (en la plataforma de abrasión) y 4 cuevas. Las cuevas tienen un desarrollo horizontal, se encuentran cercanas al nivel del mar y son pequeñas, y es la cueva Pochote 115, la que tiene mayor desarrollo, con 32,24 m (Goicoechea, 1992).

\section{Turrialba y Pacuare}

La zona kárstica de Turrialba y Pacuare incluye rocas carbonatadas de edades Eoceno Medio-Superior (tajo las Ánimas, Formación Fila de Cal,(Sprechmann et al., 1994)), Oligoceno Superior - Mioceno Inferior (Jesús María, Formación Punta Pelada; Cervantes, 1989, menciona en el río Barbilla la presencia de calizas arrecifales con un espesor máximo de $600 \mathrm{~m}$ y de edad Oligoceno Medio a Superior) y Mioceno
Superior - Plioceno Inferior (Bonilla, Linda Vista (Fernándes, 1987), son facies diferenciables en la Formación Río Banano). Las facies calcáreas de la Formación Río Banano corresponden con calizas bioclásticas, arrecifales y calcarenitas (Taylor, 1975). Fernández (1989), menciona un espesor aproximado de $15 \mathrm{~m}$ para las calcarenitas de Linda Vista, J. Espinoza (2011, com. pers.) indica que tienen espesores variables entre 10 y $45 \mathrm{~m}$ y son discontinuas lateralmente.

El karst de esta zona ha sido poco estudiado. Existen cuevas en Cabeza de Buey, Jesús María y Bonilla. J. Espinoza (2011, com. pers.) indica la presencia de cuevas y sumideros en Carazo y Quebrada Escondida. En el sector de Bonilla se exploró la cueva Huecos, la cual tiene un desarrollo sub-horizontal de $97 \mathrm{~m}$, a lo largo de una fractura con pasajes angostos, agua en la mayoría de la cueva y bastante guano (figura 5).

\section{Talamanca}

Esta es la zona kárstica menos estudiada de Costa Rica, por factores como las pocas vías de acceso que presenta, la abundante selva y lo 


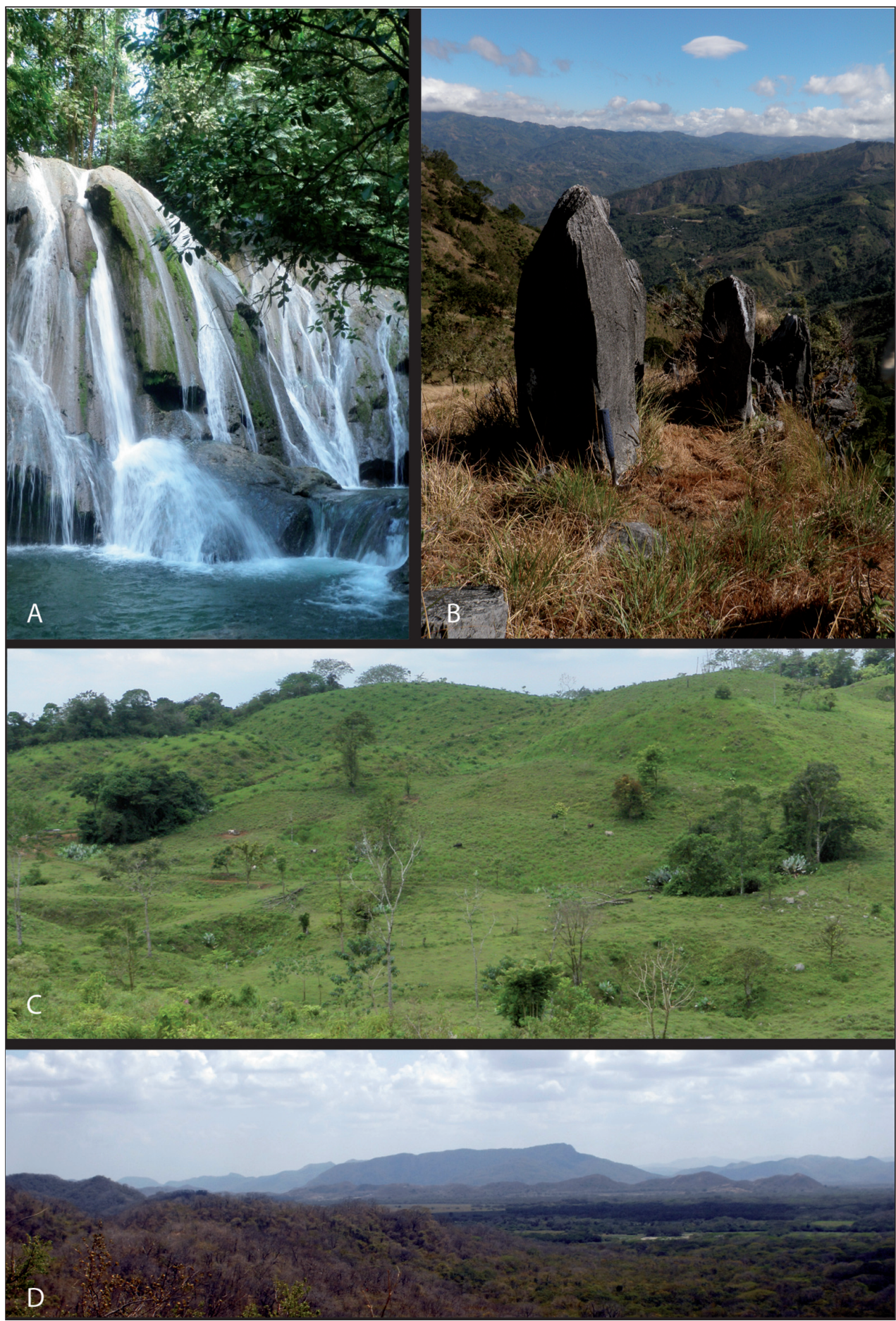

Fig. 7. Morfologías asociadas con el karsismo. A) Cascadas cubiertas de travertino, río Abrojo, Zona Sur. B) Lapiaz en la Fila Aguabuena $\left(-84.18^{\circ}, 9.72^{\circ}\right)$, Pacífico Central. C) Campo de dolinas en Bajo Bonita de Río Claro, Zona Sur $\left(-83.06^{\circ}, 8.71^{\circ}\right)$. D) Mogotes de los Cerros de Barra Honda. 


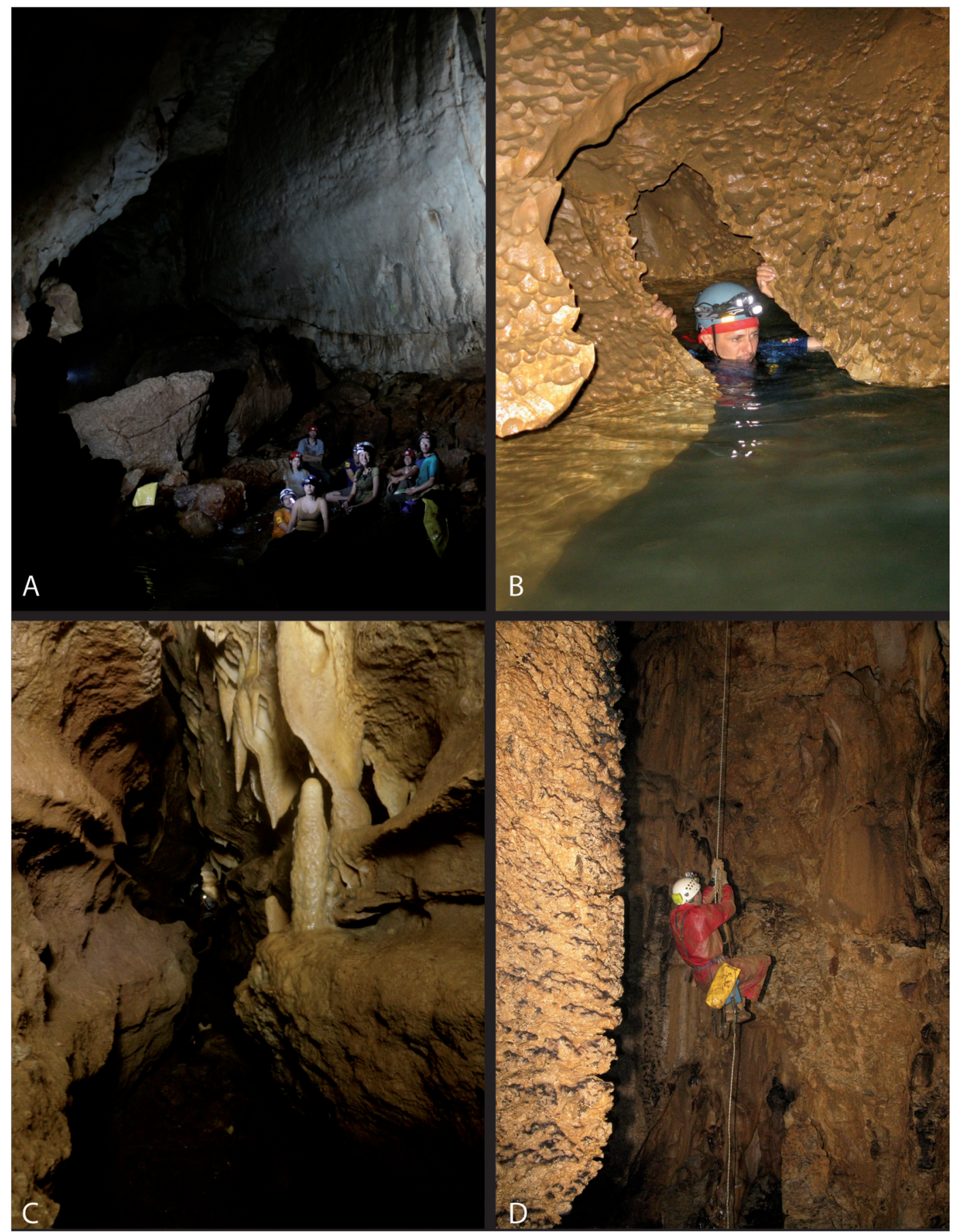

Fig. 8. Diversos pasajes encontrados en las cuevas. A) Cámara controlada por una falla dentro de la caverna Corredores. B) Sifón en la caverna Carma, Zona Sur $\left(-82.94^{\circ}, 8.67^{\circ}\right)$. C) Pasaje a lo largo de una fractura con disolución diferencial en algunos estratos, Caverna Menonitas, Venado $\left(-84.78^{\circ}, 10.56^{\circ}\right)$. D) Pasaje vertical en Pozo Miramar, en Miramar de Abrojo $\left(-82.86^{\circ}, 8.63^{\circ}\right)$. 
escarpado de las montañas. Se estima un mínimo de $10 \mathrm{~km}^{2}$ de superficie de calizas. En la quebrada Skiri, al margen sur del río Coén y cerca de San José Cabécar, Anónimo (1975) reporta la existencia de calizas bioclásticas a las cuales le atribuyen una edad Eoceno y se podrían correlacionar con la Formación Fila de Cal. En una sección del río Lari, Fisher \& Pessagno (1965) reportan calizas de colores pálidos a gris intermedio con un espesor de $60 \mathrm{~m}$ (en el sector de Quebrada Grande) y de edad posiblemente Terciario (Fila de Cal?).

El geólogo W. Rojas (2010, com. pers.) colectó una caliza de la Fila Lleskila $\left(-82.63^{\circ}\right.$, $9.64^{\circ}$ ), que según la fauna que presenta (moluscos bivalvos, específicamente Pecten sp.) se correlaciona con las calizas del Mioceno de Costa Rica (¿Formación San Miguel?). No hay cuevas reportadas en este sector, debido a que es una zona muy poco explorada desde el punto de vista espeleológico. Se incluye como una zona kárstica porque reúne todas las condiciones necesarias para el desarrollo de karsismo (altas precipitaciones, abundante $\mathrm{CO}_{2}$ orgánico que acidifiquen las aguas y fracturamiento, entre otros).

\section{Venado}

Esta zona kárstica se ubica en San Carlos, al norte del país, con un área kárstica aproximada de $21 \mathrm{~km}^{2}$. Son calizas bioclásticas de la Formación Venado, las cuales están estratificadas y se asocian a un sistema de barra arenosa carbonatada (Obando, 1986; Calvo \& Bolz, 1987). A esta formación se le asigna una edad de Mioceno Medio (Malavassi \& Madrigal, 1970) a Mioceno Superior (Sem Gupta et al., en Obando, 1986) Estas calizas se caracterizan por la presencia de macrofósiles, principalmente moluscos, equinodermos (Clypeaster), dientes de tiburón e icnofósiles.

Los fenómenos kársticos presentes son dolinas (alineadas a lo largo de fracturas), karst en conos, torres kársticas, sumideros, surgencias, ríos subterráneos y cuevas (Goicoechea, 2008). Se han identificado 26 cuevas, y la más conocida es la caverna de Gabinarraca (o Venado), por ser un destino turístico (figura 6). Las cuevas de esta zona tienen un desarrollo predominantemente horizontal, con un patrón dominado por las direcciones de fracturas y algunos pasajes siguen planos de estratificación (figura $8 \mathrm{C}$ ). En estas cuevas se han registrado espeleotemas como estalactitas, estalagmitas, columnas y flowstones, y en un sector de la caverna Menonitas, "bolas de yeso" (figura 9 C). Lachniet et al. (2004) realizaron análisis isotópicos $\left(\delta^{18} \mathrm{O}\right)$ y dataciones U-Th, en una estalagmita (8840-4920 años B.P.) y determinaron la existencia de un periodo seco, de reducida lluvia entre 8300 y 8000 años B.P.

\section{Valle Central}

La zona kárstica del Valle Central se desarrolla en calizas del Mioceno, las cuales tienen un área de exposición aproximada de $6 \mathrm{~km}^{2}$. En el este del valle, en los sectores de Patarrá, San Miguel, Navarro y Loma Salitral se encuentran calizas bioclásticas de la Formación San Miguel (Mioceno Inferior a Medio), de color gris azulado, compuestas por restos abundantes de Pecten, Balanus, ostras y algas (Fernández \& Madrigal, 1960; Carballo \& Fischer, 1978). Al oeste del valle, en el sector de Turrúcares afloran areniscas bioclásticas carbonatadas, muy fosilíferas, de poco espesor (Montero, 1974; Fischer, 1985) de edad Mioceno Inferior cuspidal a Mioceno Superior alto (Fischer, 1985).

El karsismo en el este del Valle Central puede ser considerado como "incipiente", ya que el sistema se encuentran poco desarrollado. El fenómeno más importante es la cueva conocida como El Abismo Oscuro, en Patarrá de Desamparados, característico de la zona vadosa y alcanza una profundidad máxima de 24,1 m. En el sector de Navarro se encuentran tres cuevas de desarrollo horizontal, de las cuales la de mayor longitud es la cueva Terán, que tiene $30 \mathrm{~m}$.

\section{Limón}

En las localidades de Moín, Cahuita, Manzanillo y Brazo Seco, en la provincia de Limón, se encuentran rocas calcáreas con un área 


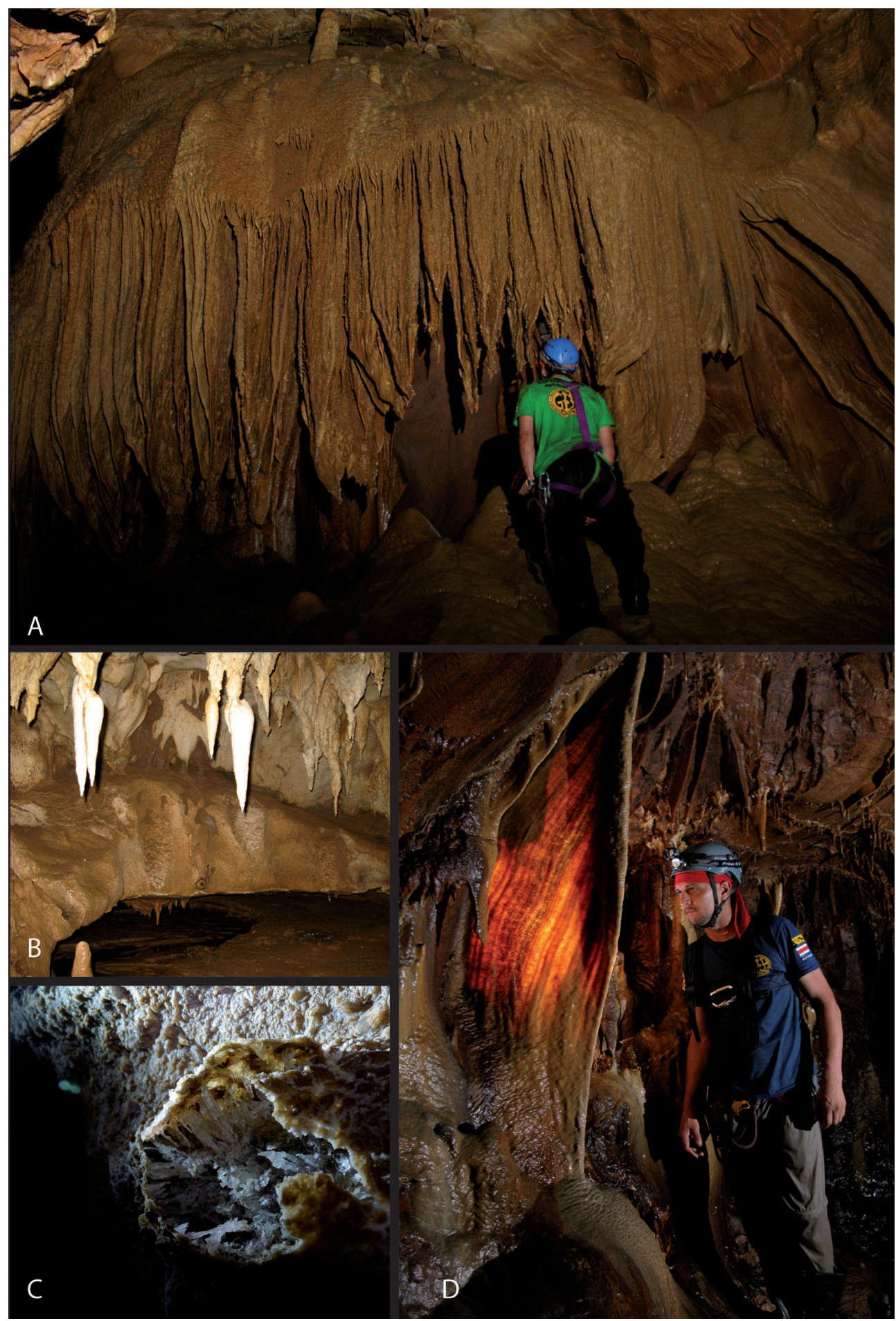

Fig. 9. Diversos espeleotemas encontrados en algunas cuevas. A) Flowstone, caverna Carma, Zona Sur. B) Estalactitas blancas, caverna Carma. C) ¿Bola de yeso? en una de las paredes de la caverna Menonitas, Venado. D) Capas de calcita depositadas en capas paralelas (draperies), caverna Carma. 
aproximada es de $20 \mathrm{~km}^{2}$. Son calizas bioclásticas y arrecifales del Plioceno al Holoceno de las formaciones Río Banano y Limón.

Aguilar \& Denyer (1994) infieren la existencia de condiciones adecuadas para la instalación de pequeñas comunidades arrecifales durante cortos periodos de tiempo, interrumpidos por caídas locales del nivel del mar y levantamientos tectónicos. Cerca de la actual línea de costa existen calizas arrecifales muy jóvenes, expuestas a procesos kársticos.

La morfología kárstica se caracteriza por la presencia de lapiaz, dolinas, surgencias, sumideros y cuevas. Ramos (2005) indica que los acuíferos kársticos de la zona presentan recarga por infiltración y recarga directa a través de las dolinas. Estas calizas se encuentran muy cerca del nivel del mar, por lo que el potencial para el desarrollo de un sistema kárstico complejo es reducido.

En esta zona se tienen registradas 8 cuevas (Cuadro 1). Entre las más importantes se encuentran las llamadas Gioconda y Capilla Portete, las cuales fueron descritas por Goicoechea (1970) como cavernas horizontales. Gilli (1996) reporta espeleotemas quebrados en algunas cuevas a causa del terremoto de Limón de 1991.

\section{Otras localidades calcáreas de Costa Rica (A, B, C y D de la Figura 2)}

A) Estas localidades no se incluyen como "zonas kársticas" por ser afloramientos muy puntuales, sin embargo, por presentar litologías similares a otras zonas kársticas no se puede descartar la existencia de fenómenos kársticos. Se mencionan cuatro localidades calcáreas que tienen un área aproximada de $3 \mathrm{~km}^{2}$. Hasta la fecha no se conoce un karsismo desarrollado, solamente algunas superficies de disolución tipo lapiaz. En la región costera de Garza, Nosara y Punta Pelada (localidad calcárea A de la Figura 2), afloran facies de barras arenosas carbonatadas de edad Oligoceno Superior- Mioceno Inferior de la Formación Punta Pelada (Baumgartner et al., 1984), las cuales se depositaron sobre sedimentos de talud de edad Eoceno Superior, incluidos en la Formación Arío (Astorga, 1987).
B) En el Cerro Huevo Frito (localidad calcárea B de la Figura 2) y alrededores, Varela (1990) describe una secuencia de alternancias de calcarenitas, calcilutitas y calizas, las cuales presentan fragmentos retrabajados de rudistas.

C) En los alrededores del Cerro Morro y Punta Conejo (localidad calcárea $\mathrm{C}$ de la Figura 2), Rivera (1990) reporta la presencia de calizas micríticas color blanco sobreyaciendo discordantemente un conjunto de estratos decimétricos de areniscas de grano medio con estratificación paralela e inclinada. Contienen muchos fragmentos fósiles de bivalvos, balanídeos y rudistas. Están intercaladas con estratos centimétricos de conglomerado bioclástico y brecha calcárea, con clastos de basalto. Estas rocas carbonatadas se correlacionan con las formaciones El Viejo (por presentar fragmentos de rudistas) y Barra Honda (caliza micríticas).

D) En Playa Panamá (localidad calcárea D) Arias \& Denyer (1992) reportan bloques de caliza con rudistas.

\section{DISCUSIÓN}

\section{Importancia del karst}

Los terrenos kársticos son muy diversos, presentan una amplia gama de formas y recursos superficiales y subterráneos. Constituyen un 10 $15 \%$ de la superficie del planeta (Palmer, 2007) y aproximadamente un $25 \%$ de la población mundial se abastece de aguas provenientes de acuíferos kársticos (Onac, 2000). En Costa Rica las áreas con karst ocupan aproximadamente $430 \mathrm{~km}^{2}$ del territorio nacional (Cuadro 1) y varias comunidades se abastecen de acuíferos kársticos (p.ej. Limón (aprox. sesenta mil habitantes), y Ciudad Neilly, Bajo Bonita y Río Claro, en la zona Sur, con un total aprox. de setenta mil habitantes) de ahí la necesidad de estudiar adecuadamente estas zonas.

El fenómeno más característico de las zonas kársticas es el desarrollo de cuevas. Las dimensiones de las cuevas se obtienen por medio de topografía subterránea. En Costa Rica se encuentran registradas unas 258 cuevas en calizas (Cuadro 
Cuadro 2

Las diez cavernas de mayor longitud de Costa Rica

\begin{tabular}{|c|c|c|c|c|c|}
\hline Caverna(s) & Des. (m) & Long. (m) & Explorada por: & $\begin{array}{c}\text { Zona } \\
\text { kárstica }\end{array}$ & Localidad \\
\hline $\begin{array}{l}\text { Sistema Bruja, } \\
\text { Rectángulo, Turu- } \\
\text { rún, Corredores* }\end{array}$ & -108 & 3872 & $\begin{array}{c}\text { GGCD (88), NSS } \\
(89-90)\end{array}$ & Zona Sur & Cerro Corredores \\
\hline Bananal* & $-72,2$ & 1028,7 & NSS (89-90) & Zona Sur & Sumidero Quebrada Seca \\
\hline Gabinarraca* & +35 & 2741 & $\begin{array}{c}\text { GE-CMCR (91), } \\
\text { NSS (91), GEA (97) }\end{array}$ & Venado & Venado de San Carlos \\
\hline Rectángulo* & $-82,7$ & 1411 & $\begin{array}{c}\text { GGCD (88), NSS } \\
(89-90)\end{array}$ & Zona Sur & Valle la Bruja, Corredores \\
\hline Carma* & -106 & 873 & AEC (87), NSS (89) & Zona Sur & Caño Seco de Corredores \\
\hline EMUS & -23 & 853 & $\begin{array}{c}\text { EMUS (88), NSS } \\
(89)\end{array}$ & Zona Sur & Las Vegas de Río Claro \\
\hline $\begin{array}{l}\text { Serpiente Dor- } \\
\text { mida }\end{array}$ & -172 & 450 & $\begin{array}{c}\text { NSS (97), CGC (98), } \\
\text { GEA (03) }\end{array}$ & Zona Sur & Miramar de Abrojo \\
\hline $\begin{array}{c}\text { Sistema Santa } \\
\text { Ana-Pozo Ciento } \\
\text { Diez }\end{array}$ & -125 & 402 & $\begin{array}{l}\text { GE-CMCR (69), } \\
\text { NSS (82), SSS (91) }\end{array}$ & Tempisque & Parque Nacional Barra Honda \\
\hline Olla Quemada & -57 & 346 & $\begin{array}{l}\mathrm{AEC}(88-89), \\
\operatorname{GEA}(10)\end{array}$ & $\begin{array}{l}\text { Pacífico } \\
\text { Central }\end{array}$ & Piedras Blancas \\
\hline Cesar Jenkins & +5 & 335 & GE-CMCR (69) & Venado & Venado de San Carlos \\
\hline
\end{tabular}

(*) Cavernas que no se ha terminado la exploración. Des.: Desnivel. Long.: Longitud. NSS: National Speleological Society (USA). GEA: Grupo Espeleológico Anthros. GE-CMCR: Grupo Espeleológico del Club de Montañeros de Costa Rica. EMUS: Grupo Emus, de Golfito. SSS: Société Suisse de Spéleologie. AEC: Asociación Espeleológica Costarricense. CGC: Carlos Goicoechea Carranza. GGCD: Gruppo Grotte Carlo Debeljak, Trieste (Italia).

1), de las cuales un $41 \%$ han sido levantadas topográficamente. Estos planos se encuentran en una base de datos denominada Speleobase, la cual es administrada por el Grupo Espeleológico Anthros (www.anthros.org). En los cuadros 2 y 3 se encuentran las cavernas más profundas y de mayor longitud de Costa Rica, así como el grupo espeleológico (o persona) que exploró y documentó la cueva, con su respectivo año.

Los sedimentos y espeleotemas dentro de las cuevas mantienen un registro continuo de las variaciones climáticas, por lo que son de gran utilidad para obtener información paleoclimatológica. Por ejemplo, a partir de una estalagmita en la caverna de Gabinarraca, Lachnient et al. (2004) determinaron un periodo seco entre 8300 y 8000 años B.P.

Las cuevas además, tienen un alto potencial de conservación del patrimonio arqueológico y cultural. Ejemplo de esto son algunas cuevas de la zona kárstica Tempisque (Nicoa: restos de cráneos (Mora, 1981); Chorotega: tiestos y falanges; La Calavera: una calavera, huesos y restos de cerámica). Constituyen asimismo, ecosistemas con condiciones particulares, donde algunos organismos se han adaptado a vivir sin luz solar (troglobios) y ocasionalmente se da una intensa acción bacteriana que contribuye a la precipitación de minerales.

En Costa Rica, algunas cuevas han sido utilizadas como atractivo turístico (Bunndschuh et al., 2007), entre ellas Terciopelo y la Cuevita, en Barra Honda (zona Tempisque); Gabinarraca, en la zona de Venado; Damas, en Quepos y Olla Quemada, en Piedras Blancas de Savegre (zona Pacífico Central); Abismo Oscuro en Patarrá (zona Valle Central) y Corredores y la Gran Galería, en Corredores (Zona Sur). Las cuevas 
Cuadro 3

Las diez cavernas de mayor profundidad de Costa Rica.

\begin{tabular}{|c|c|c|c|c|c|}
\hline Caverna(s) & Prof. (m) & Long. (m) & $\begin{array}{l}\text { Explorada por, } \\
\text { año }\end{array}$ & $\begin{array}{c}\text { Zona } \\
\text { kárstica }\end{array}$ & Localidad \\
\hline Serpiente Dormida & -172 & 450 & $\begin{array}{l}\text { NSS (97), CGC } \\
(98), \text { GEA (03). }\end{array}$ & Zona Sur & Miramar de Abrojo \\
\hline Guayabí & -142 & 230 & $\begin{array}{l}\text { NSS (90), SSS } \\
(91), \text { GEA (03) }\end{array}$ & Zona Sur & Barranquilla de Agua Buena \\
\hline $\begin{array}{c}\text { Sistema Santa Ana-Pozo } \\
\text { Ciento Diez }\end{array}$ & -125 & 402 & $\begin{array}{c}\text { GE-CMCR } \\
(69), \text { NSS (82), } \\
\text { SSS (91). }\end{array}$ & Tempisque & Parque Nacional Barra Honda \\
\hline Carma* & -106 & 873 & $\begin{array}{l}\text { AEC (87), NSS } \\
(89), \text { GEA (10) }\end{array}$ & Zona Sur & Caño Seco de Corredores \\
\hline Bananal* & $-72,2$ & 1028,7 & NSS (89-90). & Zona Sur & Sumidero Quebrada Seca \\
\hline $\begin{array}{l}\text { Sistema Bruja, Rectángulo, } \\
\text { Tururún, Corredores* }\end{array}$ & -108 & 3872 & $\begin{array}{l}\text { GGCD (88), NSS } \\
(89-90) .\end{array}$ & Zona Sur & Cerro Corredores \\
\hline Rectángulo* & $-82,7$ & 1411 & $\begin{array}{c}\text { GGCD (88), NSS } \\
(89-90) .\end{array}$ & Zona Sur & Valle la Bruja, Corredores \\
\hline La Trampa & -95 & 167 & $\begin{array}{c}\text { GE-CMCR (68), } \\
\text { CRF-76, NSS } \\
(82), \text { GEA (98). }\end{array}$ & Tempisque & Parque Nacional Barra Honda \\
\hline Sistema Tururún-Corredores & -95 & 2030 & NSS (89-90). & Zona Sur & Cerro Corredores \\
\hline Chorotega & -85 & 167 & $\begin{array}{l}\text { GE-CMCR } \\
\text { (71), CRF (76), } \\
\text { NSS (82). }\end{array}$ & Tempisque & Parque Nacional Barra Honda \\
\hline
\end{tabular}

(*) Cavernas que no se ha terminado la exploración. Des.: Desnivel. Long.: Longitud. NSS: National Speleological Society (USA). GEA: Grupo Espeleológico Anthros. GE-CMCR: Grupo Espeleológico del Club de Montañeros de Costa Rica. EMUS: Grupo Emus, de Golfito. SSS: Société Suisse de Spéleologie. AEC: Asociación Espeleológica Costarricense. CGC: Carlos Goicoechea Carranza. GGCD: Gruppo Grotte Carlo Debeljak, Trieste (Italia). CRF: Cave Research Foundatiom (USA).

de Barra Honda son las únicas que se encuentran bajo un régimen de protección (Parque Nacional Barra Honda, creado en 1974). La Zona Sur tiene un muy alto potencial para el turismo kárstico, sin embargo no ha sido desarrollado ni se encuentra bajo algún régimen de protección.

\section{Consideraciones hidrogeológicas, ambientales e ingenieriles}

Cuando se desarrollan obras de infraestructura en zonas kársticas, debe realizarse un análisis detallado, con el fin de entender el sistema, ya que estas áreas presentan condiciones ingenieriles especiales. Entre los problemas más comunes asociados al karst se encuentran:
Colapso de dolinas: Este es uno de los inconvenientes más documentados en zonas kársticas. Ocurren de manera natural, pero también pueden ser inducidos por actividades humanas. El riesgo de un potencial colapso de una dolina es mayor en las zonas donde son abundantes. Muchos colapsos de dolinas son disparados por cambios rápidos en las condiciones de aguas subterráneas (Palmer, 2007). En Costa Rica se han reportado colapsos de dolinas en la Zona Sur, Limón y Venado, aunque ninguno de estos ha presentado daños graves.

Karst y embalses: Es común que la red hidrográfica que atraviesa los terrenos kársticos se encuentre encañonada, lo cual es un factor muy bien valorado para la construcción de represas hidroeléctricas. Las represas en terrenos kársticos requieren una especial atención, ya que el agua 
embalsada se puede escapar por la red de conductos subterráneos, modificando las condiciones hidrodinámicas e hidroquímicas del sistema (Hötzl, 1999). Existen embalses en terrenos kársticos que no han presentado problemas de este tipo o se han solucionado mediante inyecciones de concreto. Otros casos, como la presa de Montejaque (Málaga, España) construida en 1920-1923, no se ha podido llenar debido a la naturaleza permeable del embalse (Carrasco, 2002). En Costa Rica, el sitio de presa Cajón del proyecto hidroeléctrico Boruca se encontraba en calizas (Fm. Fila de Cal) con karsismo desarrollado, por lo que fue un criterio para trasladar el sitio de presa aguas arriba, en una zona con mejores condiciones geológicas (A. López \& A. Cerdas, com. esc., 2011).

Contaminación de aguas subterráneas: En los acuíferos kársticos, la recarga que se produce en determinados sectores, las elevadas velocidades del agua y la presencia de sumideros, permiten que las aguas superficiales penetren directamente en la red de conductos kársticos subterráneos. En zonas de desarrollo urbano o agrícola, es común la contaminación de acuíferos kársticos, siendo los contaminantes más comunes los efluentes de tanques sépticos, derivados de hidrocarburos, desechos sólidos, productos químicos, fertilizantes, pesticidas, herbicidas, etc. En Costa Rica la ley de aguas establece zonas de protección de $100 \mathrm{y}$ $200 \mathrm{~m}$ radiales para manantiales, sin embargo, estas no son útiles en acuíferos fracturados altamente heterogéneos como los acuíferos kársticos. Pochon et al. (2008) proponen una metodología para la protección de aguas subterráneas (método DISCO) aplicable a los acuíferos kársticos, la cual toma en cuenta las discontinuidades en la roca, las características de la cobertura de suelo y la escorrentía que puede transportar contaminantes. Esta metodología o alguna similar, debería ser implementada en Costa Rica para delimitar, de una manera adecuada, las zonas de protección en acuíferos kársticos.

\section{CONCLUSIONES}

Durante la evolución geológica de Costa Rica han existido al menos 9 episodios de depositación de rocas carbonatadas (figura 1), relacionados con los procesos tectónicos, volcánicos y sedimentarios que se desarrollaron a partir del Cretácico Superior hasta el Cuaternario.

Por efectos de disolución de estas rocas carbonatadas por aguas meteóricas se producen morfologías exo y endokársticas. Con base en criterios geológico-geográficos en Costa Rica se han delimitado diez zonas kársticas y algunas zonas aisladas: 1)Pacífico Norte, 2) Tempisque, 3) Zona Sur, 4) Pacífico Central, 5) Cabo Blanco y Mal País, 6) Turrialba y Pacuare, 7) Talamanca, 8) Venado, 9) Valle Central, 10) Limón y zonas kársticas aisladas A) Garza, B) Cerro Huevo Frito,C) Cerro Morro, D) Playa Panamá.

Las zonas de Tempisque, Zona Sur y Venado, son las zonas en las que se ha cuantificado la mayor cantidad de fenómenos kársticos y se encuentran en rocas desde el Paleoceno hasta el Mioceno (Formaciones Barra Honda, Fila de Cal y Venado). En las calizas del Cretácico Superior (Formación El Viejo) no se han encontrado sistemas kársticos bien desarrollados, solamente algunas disoluciones superficiales (tipo lapiaz), sin embargo, no se descarta la posibilidad de un paleo-karst.

El desarrollo de paisajes kársticos, en las zonas estudiadas no se encuentra directamente asociado con la edad de las calizas, ya que en las calizas más viejas (Formación El Viejo, Cretácico Superior) no se encuentra un karst desarrollado y en las calizas más jóvenes (Formación Limón, Pleistoceno-Reciente) hay presencia de fenómenos kársticos como cuevas y dolinas.

Las morfologías kársticas más comunes son las superficies de disolución (lapiaz) y las dolinas. Sistemas kársticos desarrollados con sistemas de circulación de agua subterránea se encuentran en la Zona Sur, Venado, Pacífico Central, Limón y algunas cuevas en Turrialba y Pacuare. En las exploraciones espeleológicas realizadas en Barra Honda no se ha alcanzado el nivel freático, sin embargo, sí existen algunos manantiales periféricos.

Se estima que el karst ocupa un $0,85 \%$ del territorio nacional (Cuadro 1) y cubre una superficie mínima de $430 \mathrm{~km}^{2}$. Hay registro de por lo menos 258 cuevas, en rocas calizas, de las cuales un $41 \%$ se encuentran levantadas topográficamente 
(100 cuevas). El 88\% de las cuevas de Costa Rica se encuentran en las zonas kársticas de la Zona Sur (61\%), Tempisque (17\%) y Venado (10\%); el restante $12 \%$ de cuevas se distribuye en las otras zonas kársticas.

La información sobre las zonas kársticas de Costa Rica se amplía progresivamente a medida que se realizan nuevas exploraciones espeleológicas. El conocimiento de estos sistemas dista de estar completo y se espera que esta información sea mejorada en el futuro al desarrollarse nuevas investigaciones.

Con la caracterización y delimitación de las zonas kársticas de Costa Rica, se da un primer paso en el conocimiento de estos terrenos, lo cual es fundamental para el desarrollo de infraestructura habitacional, energética y de transporte, así como para prevenir la contaminación de acuíferos kársticos y optimizar el uso de los recursos asociados ya que estos sistemas son altamente heterogéneos y sensibles a la acción antrópica.

Es necesario mejorar la cartografía y la cuantificación de cada uno de los sistemas kársticos acá mencionados con sus estructuras asociadas, para que esta información sea aprovechada por las instituciones que lo ameriten con el fin de conservar y proteger estas zonas.

\section{AGRADECIMIENTOS}

Esta investigación forma parte del proyecto "Análisis de los sistemas kársticos de Costa Rica: descripción y clasificación para un manejo integral", No 830-B0-254, inscrito en la Vicerrectoría de Investigación de la Universidad de Costa Rica. Se agradece al Grupo Espeleológico Anthros por facilitar información compilada durante más de 40 años de exploraciones espeleológicas. Se agradece a Gustavo Quesada por facilitar las fotografías utilizadas en las figuras 8 B, 9 A, 9 B y 9 D; Scott Tresscott por las fotografías 8 A y 9 C; Bernald Lips por la fotografía $8 \mathrm{D}$ y Percy Denyer por la fotografía $7 \mathrm{D}$. Se agradecen los aportes verbales y escritos de J. Espinoza, W. Rojas, G.J. Soto, A. Cerdas y A. López sobre diferentes aspectos citados en el texto. De igual manera se agradece al geólogo Gerardo J. Soto por sus valiosas sugerencias y aportes.

\section{REFERENCIAS}

AGUILAR, T. \& DENYER, P., 1994: Bioestratigrafía del parche arrecifal de la quebrada Brazo Seco, Plio-Pleistoceno, Limón, Costa Rica.- Rev. Geol. Amér. Central, 17: 55-66.

ANÓNIMO, 1975: Proyecto de investigación minera, Costa Rica, Talamanca.- 61 págs. ONU, Nueva York.

ARIAS, O. \& DENYER, P., 1992: Mapa geológico de la hoja Carrillo Norte, Guanacaste, Costa Rica.- Escala 1:50 000, IGN, San José.

ASTORGA, A., 1987: El Cretácico Superior y el Paleógeno de la vertiente pacífica de Nicaragua Meridional y Costa Rica Septentrional, origen, evolución y dinámica de las cuencas profundas relacionadas al margen convergente de Centroamérica.250 págs. Univ. de Costa Rica, San José [Tesis Lic.].

BANDINI,A.N.,FLORES,K.,BAUMGARTNER, P., JACKETT, S.J. \&DENYER, P., 2008: Late Cretaceous and Paleogene Radiolaria from the Nicoya Peninsula, Costa Rica: a tectonostratigraphic application.Stratigraphy, 5(1): 3-21.

BOTTAZI, G.,FERNÁNDEZ, J.A. \& BARBOZA, G., 1994: Sedimentología e historia tectono-sedimentaria de la cuenca de Limón Sur.- Profil, 7: 351-389.

BOLZ, A. \& CALVO, C., 2002: Calizas lutetianas del arco interno Paleógeno de Costa Rica.Rev. Geol. Amér. Central, 26: 7-24.

BAUMGARTNER, P. O., MORA, C., SIGAL, B.J., GLACON, G., AZÉMA, J. \& BOURGOIS J., 1984: Sedimentación y paleogeografía del Cretácico y Cenozoico del litoral pacífico de Costa Rica.- Rev. Geol. Amér. Central, 1: 57-136. 
BUNDSCHUH, J., BIRKLE, P., FINCH, R.C., DAY, M., ROMERO, J., PANIAGUA, S., ALVARADO, G.E., BHATTACHARYA, P., TIPPMANN, K. \& CHAVES, D., 2007: Geology-related tourism for sustainable development.- En: BUNDSCHUH, J. \& ALVARADO, G.E. (eds.): Central America: geology, resources and hazards.- Ed. Taylor \& Francis, London, 2: 1015-1098.

CARBALLO, M.A. \& FISCHER, R., 1978: La Fm. San Miguel (Mioceno, Costa Rica).Inf. Sem. IGN: 45-144.

CALVO, C., 1987: Las calizas neríticas de la vertiente Pacífica del norte de Costa Rica y sur de Nicaragua: Épocas y sistemas asociados con la apertura y evolución del margen convergente de la América Central meridional.- 165 págs. Univ. de Costa Rica, San José [Tesis Lic.].

CALVO, C. \& BOLZ, A., 1987: La secuencia de Venado, un estuario Lagunar del Mioceno Medio, San Carlos, Costa Rica.- Rev. Geol. Amér. Central, 6: 1-24.

CALVO, C. \& BOLZ, A., 1991: La Formación Espíritu Santo (Costa Rica): Sistemas de plataforma carbonatada autóctona del Paleoceno Superior-Eoceno Inferior.- Rev. Geol. Amér. Central, 13: 91-95.

CARRASCO, F., 2002: Karst y medio ambiente. Perspectiva desde Andalucía (España).En: CARRASCO, F., DURÁN, J.J. \& ANDREO B. (Eds.): Karst and environment: 19-29.

CASTILLO, R., 1969: Geología de los mapas básicos Abra y parte de Rio Grande, Costa Rica.- 40 págs. Informe MEIC, San José [Inf. Interno].

CASTILLO, R., 2011: Glaciaciones e interglaciaciones en Costa Rica: realidades y enigmas geológicos.- 197 págs. Ed. Litografia e Imprenta LIL. San José, Costa Rica.
DENGO, G., 1962: Estudio geológico de la región de Guanacaste, Costa Rica.- Inf. Sem. IGN: 1-112.

DENYER, P. \& ALVARADO, G., 2007: Mapa Geológico de Costa Rica.- Escala 1:400 000, Librería Francesa S.A., San José, Costa Rica.

FERNÁNDEZ, J., 1987: Geología de la hoja topográfica Tucurrique. Escuela Centroamericana de Geología.- 205 págs. Univ. de Costa Rica, San José [Tesis Lic.].

FERNÁNDEZ, M. \& MADRIGAL, R., 1960: Calcáreos y calizas de la zona de Patarrá.17 págs. Dirección de Geología Minas y Petróleo [Inf. Interno].

FISCHER, R., 1985: La fauna de la Formación Turrúcares (Mioceno, Valle Central, Costa Rica).- Geologica et Paleontologica, 19: 191-225.

FISCHER, R. \& AGUILAR, T., 1994: Paleontology of an evolving island arc.PROFIL, 7: 391-400.

FISHER, S.P. \& PESSAGNO, E.A., 1965: Upper Cretaceous strata of northwestern Panamá.The American Association of Petroleum Geologists, 49: 433-444.

FISHER, D.M., THOMAS, W.G., SAK, P.B., SANCHEZ, J.D., MURPHY, K. \& VANNUCCHI, P., 2004: Active thrusting in the inner forearc of an erosive convergent margin, Pacific coast, Costa Rica.Tectonics. 23, 1-13.

GILLI, E., 1994: Reconnaissance sur la neotectonique dans les karst du Costa Rica. -Centre d'Etude du karst.- Rue Masséna 06300 Nice., 13: 1-52.

GILLI, E., 1996: Effets des sêismes dans l'endokarst. Aplication aux études de sismicité historique. Mélanges Maurice 
Julian.- Revue d'Analyses Spatiable Quantitative et Appliquée, Nice, (38-39): 121-132.

GOICOECHEA, C., 1970: Macizos calcáreos y fenomenología kárstica de Costa Rica.178 págs. San José, Costa Rica [inédito].

GOICOECHEA, C., 1989: El sistema kárstico de Barra Honda y vecindades.- 88 págs. Colección "Cavernas de Costa Rica" N ${ }^{\circ} 1$ [Inédito].

GOICOECHEA, C., 1992: La zona calcárea/ kárstica de Mal Paíis, Pen. de Nicoya (Puntarenas, C.R.).- 35 págs. Colección "Cavernas de C. R." No 9 [Inédito].

GOICOECHEA, C., 2008: La caverna de "Gabinarraca" (o Cavernas de Venado) y los sistemas kársticos aledaños.- 160 págs. EUNED, San José, Costa Rica.

GOICOECHEA, C., QUESADA, G. \& ULLOA, A., 2009: Evolution of speleology in Costa Rica.- $15^{\text {th }}$ International Congress of Speleology. Kerville, Texas, USA. 3: 1985.

GRANADOS, R. \& AGUILAR, T., 1983: Geopaleontología de la cuenca baja del río Savegre, Costa Rica.- Brenesia, 21: 229260.

HAPKA, R., BRASEY, J., GOICOECHEA, C., JEANIN, P.Y. \& JEANNIN, V., 1992: Speleo Tropicale: Explorations dans les karsts tropicaux du Costa Rica.- Caverns: Bulletin des Sections Neuchâteloises de la Société Suisse de Spéléologie, 1: 1-27.

HEMPEL, J.C., 1989: Report of the 1982 expedition to Barra Honda National Park: Caves and karst of Barra Honda National Park.- 52 págs. Ed. National Speleological Society, USA.
HEMPEL, J.C., VENN, C. \& STORRICK, G., 1993: Karst geology on the Corredor River basin.- En: PEACOCK, D. \& HEMPEL, J. (Eds.): Studies in the río Corredores basin.NSS Journal of Caves and Karst, 55: 5-31.

HÖTZL, H., 1999: Industrial and urban produced impacts.- En: DREW, D. \& HÖTZL, H. (Eds.): Karst hydrogeology and human activities: impacts, consequences and implications.- Balkema, Rotterdam: 81-184.

KUENY, J.A., DAY, M.J., 2002: Designation of protected karstlands in Central America: a regional assessment.- J. of Caves and Karst Stud. 64(3): 165-174.

LACHNIET, M.S., ASMERON, Y., BURNS, S., PATTERSON, W.P., POLYYAK, V., SELTZER, G.O., 2004: Tropical response to the $8200 \mathrm{yr}$ B.P. cold event? Speleothem isotopes indicate a weakened early Holocene monsoon in Costa Rica.- Geol. 32 (11): 957-960.

LOHMANN, W., 1934: Stratigraphie und tektonik des Hochlandes von Costa Rica.- Geol. Rundschau, 25: 10-26.

MALAVASSI, E., 1961: Some Costa Rican larger foraminiferal localities.- J. Paleont. 35: $498-501$.

MALAVASSI, V.E. \& MADRIGAL, R., 1970: Reconocimiento geológico de la Zona Norte de Costa Rica.- Inf. Tec. y Not. Geol. (38): 1-18 San José, Costa Rica.

MARTINI, J.E.J., 2000: Quartzite caves in Southern Africa.- En: KLIMCHOUCK, A.B., FORD, D.C., PALMER, A.N. \& DREYBRODT, W. (Eds.) Speleogenesis: Evolution of Karst Aquifers.- 527 págs. Ed. National Speleological Society, Alabama, EE.UU: 458-461. 
MCNEILL, D.F., COATES, A.G., BUDD, A.F. \& BORNE, P.F., 2000: Integrated paleontologic and paleomagnetic stratigraphy of the upper Neogene deposits around Limon, Costa Rica: A coastal emergence record of the Central American Isthmus.- Geol. Soc. Am. Bulletin, 112(7): 963-981.

MONTERO, W., 1974: Estratigrafía del Cenozoico del área Turrúcares, provincia de Alajuela, Costa Rica.- 40 págs. Univ. de Costa Rica, San José [Inf. Campaña Geol.].

MORA, S., 1978: Estudio geológico de los cerros Barra Honda y alrededores, cantón de Nicoya, provincia de Guanacaste, Costa Rica.- 173 págs. Univ. de Costa Rica, San José [Inf. Campaña Geol.].

MORA, S., 1981: Barra Honda.- 94 págs. Editorial Universidad Estatal a Distancia, San José, Costa Rica.

MORA, S., 1986: Consideraciones sobre el karsismo costarricense.- 19 págs. Instituto Costarricense de Electricidad [Inf. interno].

MORA, S., 1987 : Les regions karstiques du Costa Rica et leur contexte géologique.Karstología 10(2): 25-32.

MORELL, K., FISHER, D.M. \& GARDNER, T.W., 2008: Inner forearc response to subduction of the Panama Fracture Zone, southern Central America.- Earth and Planetary Science Letters, 265: 82-95.

OBANDO, L.G., 1986: Estratigrafía de la Formación Venado y rocas sobreyacientes (Mioceno-Reciente) Provincia de Alajuela, Costa Rica.- Rev. Geol. Amér. Central 5: 73-104.

OBANDO,L.G. \& KUSSMAUL, S., 2009: Geología de la hoja Buenos Aires, Costa Rica.- Rev. Geol. Amér. Central, 41: 123-136.
ONAC, B.P., 2000: Geologia regiunilor carstice.399 págs. Editura Didactiă şi Pedagogică, Bucharest Romania.

OLSSON, A., 1942: Tertiary and Quaternary fossils from the Burica Penninsula of Panama and Costa Rica.- Bulletin of American Paleontology, 27(106): 1-106.

PALMER, A., 2007: Cave Geology.- 454 págs. Ed. Cave Books, Dayton, EE. UU.

PEACOCK, D. \& HEMPEL, J. (Eds.), 1993: Studies in the rio Corredores basin.- NSS Journal of Caves and Karst, 55.

POCHON, A., TRIPET, J.P., KOZEL, R., MEYLAN, B., SINREICH, M., ZWAHLEN, F., 2008: Groundwater protection in fractured media: a vulnerabilitybased approach for delineating protection zones in Switzerland.- Hydrogeol. J. 16: 1267-1281.

RAMOS, V., 2005: Estudio hidrogeológico y vulnerabilidad del acuífero Moín, Limón.- 87 págs. Univ. de Costa Rica, San José [Tesis Lic.].

RIVERA, S., 1990: Estudio geológico de la zona entre Matapalo y Cabo Velas, Provincia de Guanacaste.-18 págs. Univ. de Costa Rica, San José [Inf. Campaña Geol.].

RIVIER, F., 1983: Síntesis geológica y mapa geológico del Área del bajo Tempisque, Guanacaste, Costa Rica. Inf. Sem. IGN, (1): 7-37.

SEYFRIED, H., ASTORGA, A., AMANN, H., CALVO, C., KOLB, W., SCHMIDT, H.\& WINSEMANN, J., 1991: Anatomy of an evolving island arc: tectonic and eustatic control in the south Central American forearc area.- Spec. Publs. Int. Ass. Sediment, 12: $217-240$. 
SCHMIDT-EFFING, R., 1974: El primer hallazgo de ammonites en América Central Meridional y notas sobre las facies cretácicas en dicha región.- Inf. Sem. IGN: 53-61.

SITCHLER, J.C., FISHER, D.M., GARDNER, T.W. \& PROTTI, M., 2007: Constraints on inner forearc deformation from balanced cross sections, Fila Costeña thrust belt, Costa Rica.- Tectonics, 26. DOI: 10.1029/2006TC001949.

SOTO, G.J., 1985: Estudio geológico entre La Pita y río Camaronal, provincias de Puntarenas y San José.- 40 págs. Univ. de Costa Rica, San José [Inf. Campaña Geol.].

SPRECHMANN, P., ASTORGA, A., FERNÁNDEZ, A. \& CALVO, C., 1994: Cuadro sinóptico de correlación estratigráfica de las cuencas sedimentarias de Costa Rica.- Profil 7: 427-431.
TAYLOR, G.D., 1975: The geology of the Limon area of Costa Rica.- 116 págs. Louisiana State University and Agricultural and Mechanical College [Tesis Ph.D.]

ULLOA, A., 2009: Caves of Costa Rica (Central America) and their geologic origin.- $15^{\text {th }}$ International Congress of Speleology. Kerville, Texas, EEUU. 3: 1930-1935.

VARELA, G., 1990: Estudio e interpretación geológica del área sur de Belén, Guanacaste.72 págs. Univ. de Costa Rica, San José [Inf. Campaña Geol.].

WELLS, S., 1974: Geologic reconnaisance of the Cerros Barra Honda Karst Costa Rica.- 15 págs. University of Cincinnati, USA.

YUAN, P., 1984: Stratigraphy, sedimentology and geologic evolution of eastern Térraba trough, southwestern Costa Rica.- 110 págs. Louisiana State University, USA [Tesis Ph.D.] 